\title{
Flexibility and robustness of a high-temperature air/ceramic thermocline heat storage pilot
}

\author{
Lopez Ferber Nicolas ${ }^{\mathrm{a}, \mathrm{b}, \mathrm{c}, *}$, Q. Falcoz ${ }^{\mathrm{a}}$, D. Pham Minh ${ }^{\mathrm{b}}$, J.F. Hoffmann ${ }^{\mathrm{c}}$, A. Meffre ${ }^{\mathrm{c}}$, A. Nzihou ${ }^{\mathrm{b}}$, \\ V. Goetz ${ }^{\mathrm{a}}$ \\ a PROMES-CNRS UPR-8521 Laboratory, University of Perpignan Via Domitia, Rambla de la Thermodynamique, Tecnosud, F66100, Perpignan, France \\ ${ }^{\mathrm{b}}$ RAPSODEE-CNRS UMR-5302, Mines Albi, Université de Toulouse, Campus Jarlard, F81013, Albi cedex 09, France \\ ' SAS Eco-Tech Ceram, Espace Entreprises Méditerranée, rue Edouard-Belin, F66600, Rivesaltes, France
}

\begin{abstract}
A B S T R A C T
A high-temperature air/ceramic thermocline packed-bed heat storage pilot was designed and built to measure the effects of operating parameters and quality of the heat resource on its performance, with a horizontal duct of square section. The influence of inlet air flow rate during the discharging phase and the impact of a degraded inlet heat resource during the charging phase were studied. The results revealed that the horizontal orientation of the bed didn't generate a thermal radial gradient. Results also show that the overall cycle efficiency is weakly affected by the changes in the operating conditions. Thermocline heat storage is surprisingly well-suited to managing resource instabilities. It forms a robust, flexible high temperature storage system applicable for industrial use to recover and deliver erratically produced waste heat.
\end{abstract}

Keywords:

Thermal energy storage (TES)

Industrial waste heat

Thermal behaviour

High temperature

Air

\section{Introduction}

The French Agency for Energy reports that industrial waste heat can represent up to $60 \%$ of inlet process energy in heavy industries, most of it in high-temperature exhaust gases [1]. The US Department of Energy has estimated that these streams may represent around $20 \%$ of the input energy of steelmaking processes, and above $25 \%$ for the glass, aluminium and foundry industries [2]. To increase industrial energy efficiency, some technical solutions have been developed to recover waste heat, the best known being heat exchangers (sometimes coupled to a boiler and turbine for electricity production) and regenerators (mostly found in glass or smelting industries, associated with gas burners [3]), functioning as a buffer storage for continuous processes, but significant quantities of energy are still lost in the heavy industries [4].

The Concentrated Solar Power (CSP) industry has also developed thermal storage systems, the most mature to date being the "two-tanks molten salt" system, which uses heat exchangers and synthetic oil and/ or nitrate molten salts. These heat transfer fluids are limited in temperature range and present the drawbacks of being respectively flammable and oxidizing, limiting their applicability.

The 2008 DOE [2] study highlighted the need for thermal storage systems that could operate over a wide range of exhaust gas temperatures, be reasonably compact and cost-effective, and could maintain their performance in a broad range of situations. Gas/ceramic thermocline heat storage systems are promising for these applications. The fact that the carrier gas can be sent through a packed bed or structured bed of ceramics avoids the complexity of heat exchangers. This type of system has also been studied for high-temperature central receiver CSP [5], and adiabatic compressed air energy storage systems [6-9]. Thermocline systems are also considered with liquid HTF such as oil or molten salts, and appear promising for parabolic though CSP $[10,11]$.

Most studies of thermocline systems (using either liquids or gas as HTF) focus on three different aspects. The first mainly concerns modelling heat transfer and convection correlation. These studies are at the interface between computational fluid dynamics and heat transfer. They are mainly focused on the quality of the heat transfers between the HTF and the storage material, both of these elements exhibiting variations in properties depending on temperature. The fact that thermocline systems are always in a transient state implies dynamic modelling [12-16]. The second aspect studied is the influence of the storage material. The nature and shape of the storage materials influence the quality of heat transfers with the HTF, and on pressure drop in the system, a key aspect of systems using compressible fluids like gases. Improving the performance of materials (thermal capacity, environmental impacts and production costs) needs studies of the thermal behaviour and thermal stability of these materials, sometimes produced

\footnotetext{
* Corresponding author at: PROMES-CNRS UPR-8521 Laboratory, Rambla de la Thermodynamique, Tecnosud, F66100, Perpignan, France.

E-mail address: nicolas.lopez-ferber@promes.cnrs.fr (L.F. Nicolas).
} 


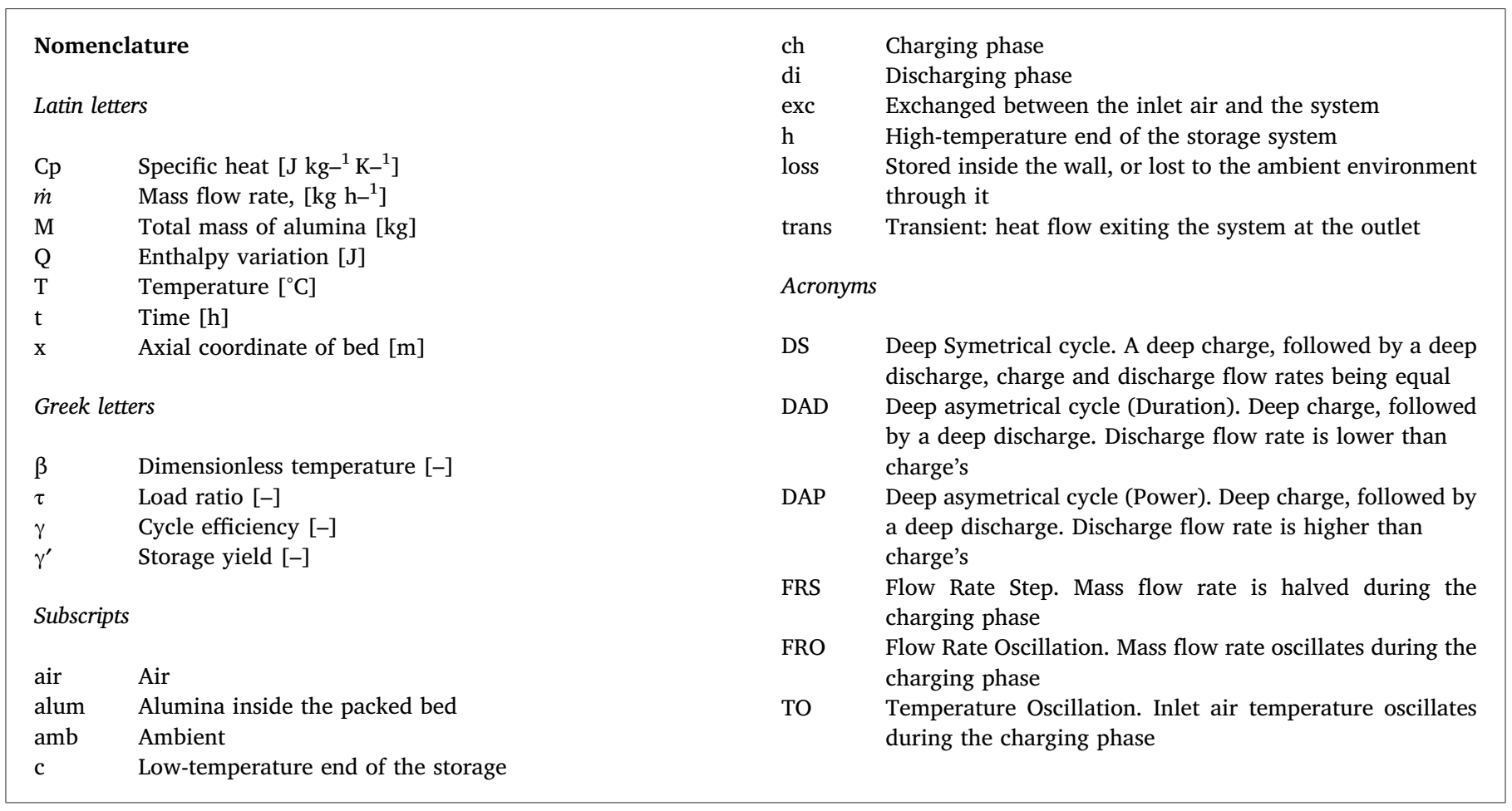

from industrial by-products (metallurgical slags, vitrified asbestoscontaining wastes, coal fly ash, etc.) [17-22]. It is commonly accepted that decreasing particle size reduces the length scale for conduction, which is reflected by a lower value of the Biot number, limiting intraparticle thermal gradients, but at the cost of an increase in the pressure drop, requiring a trade-off between transfer quality and pressure drop [23]. These issues have been reviewed by T. Esence et al., providing a good insight into thermocline modelling [24]. The third aspect is focused on the influence of the operating conditions and industrial integration. Unlike storage systems involving physical separation of cold and heat fluids (like the "two-tank molten salts" concept), the performance and behaviour of thermocline systems depend strongly on operating conditions. These operating conditions are imposed by the processes that emit waste heat streams, and by those meant to receive the heat delivered during the discharging phase. Depending on the aim of the storage, its monitoring and performance will be different [11,25-28]. The performance and industrial relevance of thermocline heat storage systems will mostly depend on the temperature thresholds (cut-off temperatures) during charge and discharge [11], which control the system's utilization factor.

Pilot-scale systems have been built and operated as research tools in the thermal engineering research community, and usually compared with simulation results $[29,30]$. The main goal is usually to measure the influence of operating conditions and particle size of the packing on performance, and to compare it with numerical models based on dimensionless numbers such as the Nusselt number. Some authors opted to focus on pressure drop along the bed, which can be a critical aspect when using industrial scale gas systems [31]. Zarrinehkafsh and Sadrameli [32] built a small fixed-bed regenerator and operated it with balanced and unbalanced cycles. They found that efficiency increased as compacity of the bed increased, and that shorter charging periods increased efficiency. They also report that increasing fluid velocity through the bed decreased efficiency, although they state that their experimental domain for mass flow rate was too restricted to reveal significant variation of efficiency (flow rate range $0.01-0.015 \mathrm{~kg} / \mathrm{s}$ ). Klein et al. [5] worked on a higher-size packed-bed pressurized bed, intended to be used as thermal storage for a solar gas turbine (hybridization): the main storage function was not to power a turbine alone, but complement a gas turbine, or preheat combustion air for the turbine. This allows the storage discharge to be deeper, so a higher proportion of stored heat is recovered, increasing efficiency and utilization factor. Zanganeh et al. [33] worked on a pilot-scale (max capacity $6.5 \mathrm{MWh}_{\text {th }}$ ) truncated conical packed bed of rocks, using air at $650^{\circ} \mathrm{C}$ as HTF. The conical shape reduced mechanical constraints and heat losses, but at the expense of increased pressure drop in the packed bed. They compared the experimental data with simulated data, using a 1D fluid model based on thermal transfer correlations inside the packed bed, including radiative transfer, and found a good fit. They chose a low charging cut-off temperature of below $100^{\circ} \mathrm{C}$, and a high charging duration of $110 \mathrm{~h}$. In view of the low outlet temperature, at the end of the charge, $86 \%$ of the input heat had been stored in the packed bed, with $13 \%$ heat losses through the insulants and less than $1 \%$ exiting the storage at the bottom end of the storage. They repeatedly cycled the system, to reach steady-cyclic behaviour, with overall efficiency exceeding $90 \%$, including the blower power requirements to circulate the air.

The company Eco-Tech Ceram (www.ecotechceram.com) develops a high-temperature (up to $900^{\circ} \mathrm{C}$ ) air/ceramic thermocline system (named EcoStock) of capacity around $3 \mathrm{MWh}$, designed to be cost-effective and compact, which may be used as storage for up to several hours, or as a buffer for continuous processes (e.g. glass industry regenerators). It presents a square section and a horizontal orientation, allowing it to be integrated into a standard naval 20 feet container. The work reported here concerns an experimental packed bed pilot at a small but representative scale. The first objective of the $45 \mathrm{~kW} \mathrm{~h}$ storage capacity (at $600^{\circ} \mathrm{C}$ ) pilot is to assess the influence of the horizontal orientation of packed bed on the thermal behaviour of the storage tank. Such configuration, relevant on a practical point of view could lead to several kind of dysfunction on the thermocline's behaviour. The U.S. Department of Energy underlines that a key feature of industrial waste heat is its diversity in terms of resource, and the fact that in many cases (especially in discontinuous processes), the heat resource is degraded (e.g. varying flow rate and/or temperature). This variability hinders the applicability of heat exchangers, highlighting the need for a compact, cost-effective, robust and flexible thermal storage system compatible with direct use of waste heat streams. To our knowledge, there are no 
reports on experimental works regarding, in the case of a high temperature storage with air as the HTF, the influence of discharge flow rate over performances on a meaningfull range. This is the second objective of the experimental work presented in this paper with. Supposed to be implemented at the outlet of different kind of industries with nonconstant waste heat resources in terms of heat flows and/or temperatures, such a storage system has to be able to manage such erratic heat resources during charges. To demonstrate, with dedicated experiments, this key functionality is the third objective of the presented work.

\section{Experimental thermal energy storage (TES)}

Most of the experimental thermocline systems described in the literature are built on the same pattern, with an insulated cylindrical vessel filled with a thermal storage material (usually rocks or ceramics), and set vertically [5,34], the cylindrical shape of the vessel being a satisfying building choice, and the vertical position countering the buoyancy effect when the hot fluid is injected/retrieved at the top. Some authors have also explored other geometries, such as the truncated cone of Zanganeh et al. [33], who used this shape to lessen mechanical constraints, and so improve the viability of the process when industrially upscaled. Even though most of the thermocline storage systems developed for the CSP industry present a cylindrical shape, most of the air/ceramic regenerative storage systems are equipped with a square duct. To our knowledge, horizontal thermocline systems are not commercialized. They present some disadvantages compared to vertical systems:

- The countering of buoyancy effect is supposed to be lessen than with vertical systems

- Whereas the section of a vertical packed bed present uniform porosity for a scaled-up thermocline systems, the horizontal ones can present a high porosity on the top of the bed, resulting in the development of a preferential path for air, allowing it to by-pass the bed.
But in terms of mechanical constraints, the higher contact surface between the ground and the storage implies minimal load on the system. The requirements for insulation can also be lowered, partially due to the fact that a significant fraction of the outer surface of the system is protected from natural convection with ambient air. This orientation can be advantageous, if the fraction of the air flow bypassing the packed bed is negligible.

The EcoStock device, made to fit a standard 20-foot shipping container, comprises a horizontal duct of square section, and has been designed so it can be moved easily, or stockpiled to increase thermal capacity. The pilot (Figs. 1 and 2) was built with the same design. During the charging phase, ambient air was pumped by a $4 \mathrm{~kW}$ centrifugal air blower regulated by a flowmeter. This air was heated up by an electrical air heater up to the required temperature (the heated air was vented until the air heater was stable), and then injected at one end of the storage vessel. The outlet air exiting the vessel was vented. During the discharging phase, the electrical air heater was by-passed by valves, and ambient air entered the storage vessel by the opposite end. The hot outlet air was vented. After a charge, inverting the flow required about $12 \mathrm{~min}$, to let the air heater cool down and manually operate the valves.

The inner configuration of the storage vessel is depicted in Fig. 2. It was composed of a $1.5 \mathrm{~m}$ long porous bed of alumina rubble (characteristic lenght $20 \mathrm{~mm}$, bed porosity $41 \%$, total mass $M=281 \mathrm{~kg}$ ), enclosed in a square-section $(0.3 \times 0.3 \mathrm{~m})$ horizontal duct built with $10 \mathrm{~cm}$ thick vermiculite slabs. The bed was contained at the two ends by perforated steel plates. The duct was placed inside an insulated steel vessel, using rockwool as insulant. The pilot was equipped with $39 \mathrm{~K}$ type thermocouples, mostly located in the packed bed, axially every $17.5 \mathrm{~cm}$ (dots in Fig. 2), and radially at three positions (dashed lines in Fig. 2). Several thermocouples were also installed in the different layers of insulants around the bed (vermiculite and rockwool)

The first $\left(T_{h}\right)$ and last $\left(T_{c}\right)$ thermocouples in the system were located respectively $5 \mathrm{~cm}$ from the left and right ends of the bed, the $5 \mathrm{~cm}$ thick
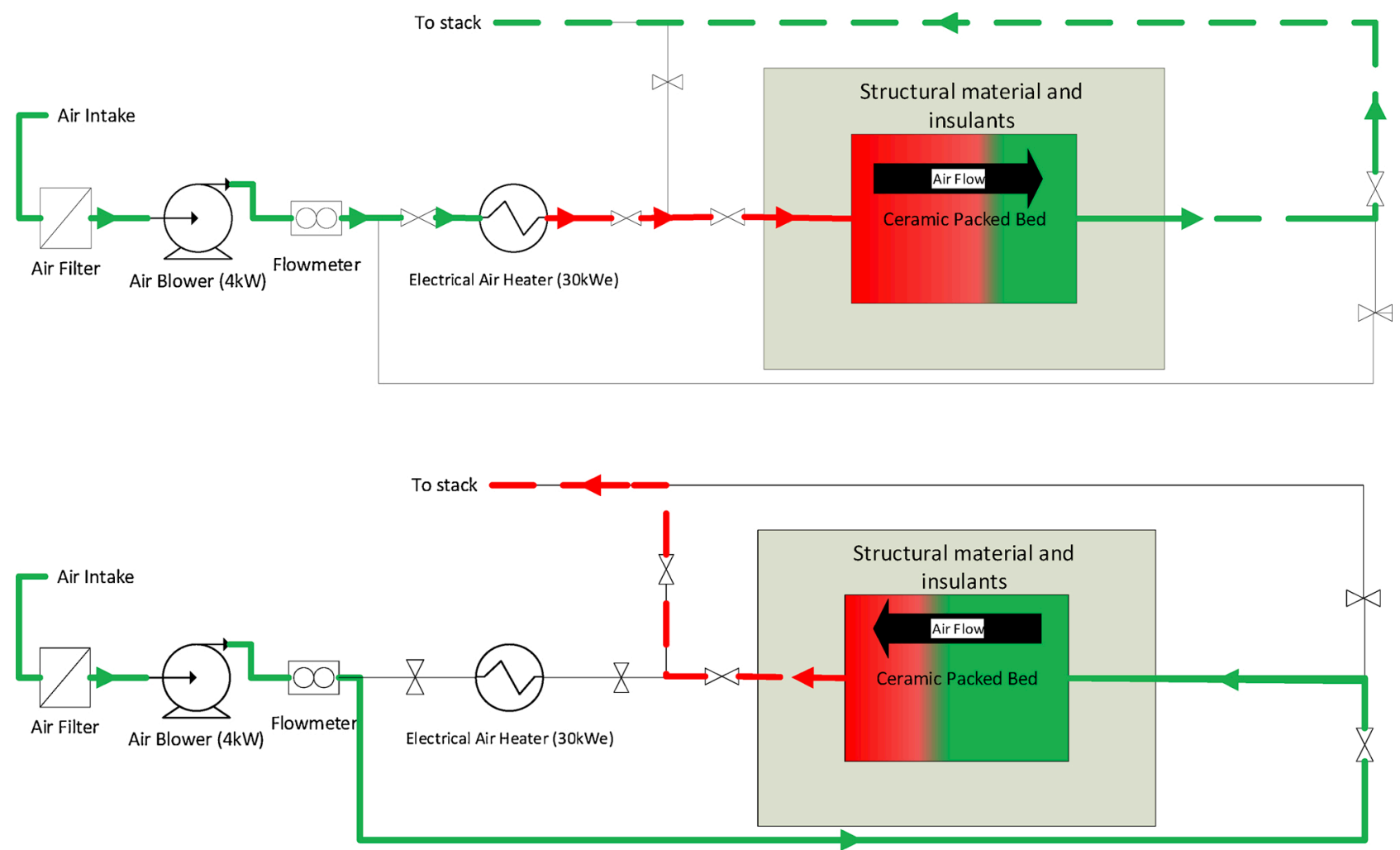

Fig. 1. System configuration in charging phase (top) and discharging phase (bottom). Green: air circuit at low temperature. Red: air circuit at high temperature. Dashed lines: storage outlet flows (For interpretation of the references to colour in this figure legend, the reader is referred to the web version of this article). 


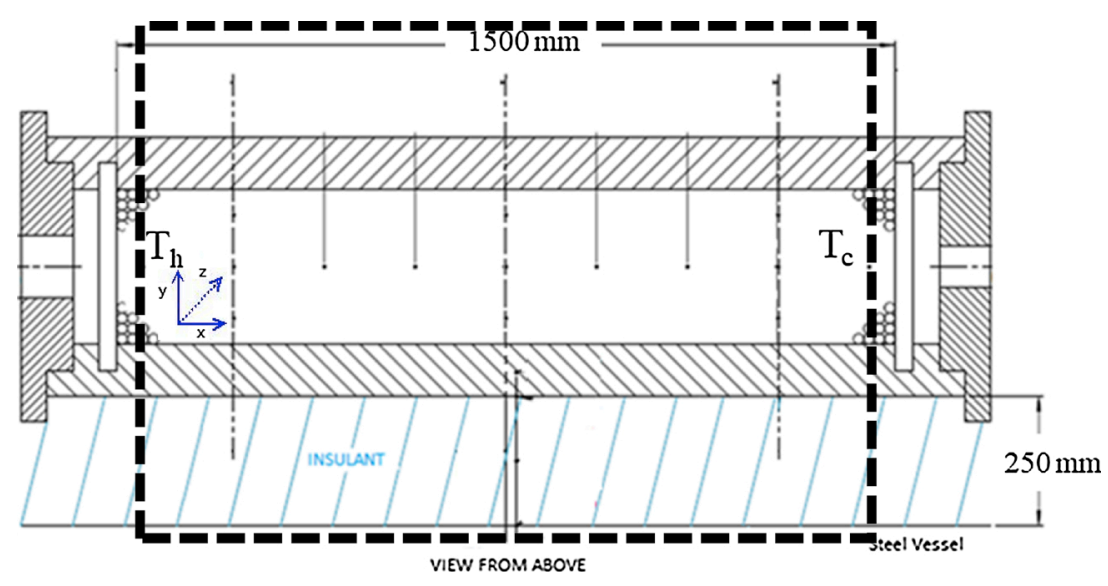

Fig. 2. Duct simplified scheme.

layer of alumina rubble being considered as a diffuser. The storage system considered in this study was therefore the portion of the packed bed and the surrounding insulants for which $0.05 \leq x \leq 1.45$, with $x=y=z=0$ being the position of the left end perforated plate (bold dashed lines in Fig. 2).

\section{Dynamic thermal behaviour monitoring indicators}

\subsection{Charging phase}

Our general objective was to integrate this type of heat storage system in order to recover, as efficiently as possible, waste heat generated by industry in high-temperature gas streams. The advantage of setting up such a storage system relies directly on its ability to capture the enthalpy content of the incoming flow at high temperature during the charging phase. Ideally it is the whole enthalpy flow available at the inlet that must be stored (Fig. 3). Owing to the inherent limitations of heat transfer, these ideal conditions, which correspond to an exit temperature equal to the ambient temperature, can obviously not be met. A fraction of the available enthalpy flowing through the bed is irreversibly lost. Although a thermocline-type working mode allows us in principle to minimize this fraction, it necessarily progresses during the storage phase; it is in fact correlated to the load ratio of the system. It is therefore essential to be able to discriminate the different enthalpy flows as represented in Fig. 3, together with their time course.

The load ratio is provided by a thermal balance performed on the solid phase. At any given time, the temperature field along the packed bed is estimated through linear interpolation of the measurements given by the thermocouples, assuming the temperature differences between the air and the ceramic fragments are negligible at any point. This assumption is used by most authors in the literature. Given that the specific heat of alumina varies with temperature, an equation of specific heat as a function of temperature suggested by Auerkari [35] was used:
Table 1

Coefficients for alumina and air specific heat polynomials, with temperature in ${ }^{\circ} \mathrm{C}$.

\begin{tabular}{lllll}
\hline \multicolumn{1}{ll}{ Alumina } & & & Air \\
\cline { 4 - 5 } \cline { 4 - 5 } Coefficient & & & Coefficient & Value \\
$a_{1}$ & $-2.090 \mathrm{E}-09$ & & $b_{1}$ & $1.9327 \mathrm{E}-10$ \\
$a_{2}$ & $5.208 \mathrm{E}-06$ & & $b_{2}$ & $-5.8882 \mathrm{E}-07$ \\
$a_{3}$ & $-4.743 \mathrm{E}-03$ & & $b_{3}$ & 0.00057167 \\
$a_{4}$ & $2.134 \mathrm{E}+00$ & & $b_{4}$ & 0.01095578 \\
$a_{5}$ & $7.283 \mathrm{E}+02$ & & $b_{5}$ & 1004.76 \\
\hline
\end{tabular}

$C \mathrm{p}_{\text {alum }}(T)=a_{1} T^{4}+a_{2} T^{3}+a_{3} T^{2}+a_{4} T+a_{5}$

with the constants $a_{1}$ to $a_{5}$ given in Table 1 .

The experimental value of the enthalpy stored in the packed bed of alumina is therefore given by discretization into $n$ equal sub-volumes of the total bed volume:

$Q_{\text {alum-ch }}(t)=\sum_{i=1}^{n} \frac{M}{n} \int_{T_{a m b}}^{T_{i}(t)} C p_{\text {alum }}(T) d T$

with $T_{\mathrm{amb}}$ the temperature of the packed bed before initiating the charging phase, $T_{i}(t)$ the temperature of the $i^{\text {th }}$ sub-volume at time $t$ and $M$ the total mass of alumina.

This allows us to calculate a load ratio $\tau(t)$, by dividing $Q_{\text {alum-ch }}$ by the maximum energy that the packed bed could store if all its mass reached the maximum temperature $T_{\mathrm{H}}$, the temperature of the hot air at the inlet of the storage system:

$\tau(t)=\frac{Q_{\text {alum-ch }}(t)}{Q_{\text {alum-max }}}$

with

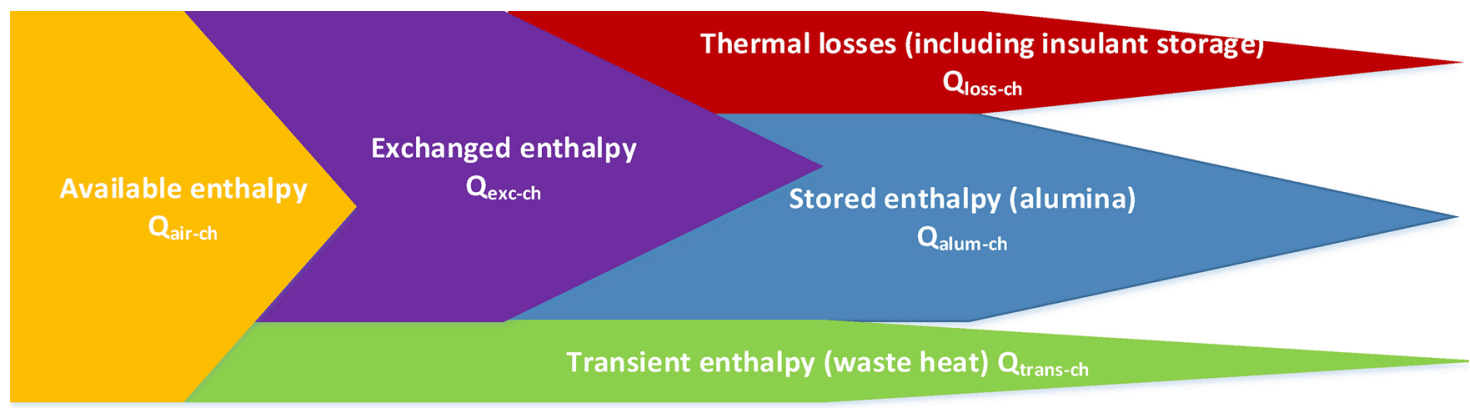

Fig. 3. Enthalpy flow distribution during the charging phase. 
$Q_{\text {alum-max }}=M \int_{T_{\text {amb }}}^{T_{H}} C p_{\text {alum }}(T) d T$

Thermal balances performed on the air are needed for a thorough understanding of the storage working mode. The heated air carries an enthalpy content. The maximum enthalpy that this air could exchange with the system is calculated at any given time by:

$Q_{\text {air-ch }}(t)=\int_{0}^{t} \dot{m}(t)\left(\int_{T_{a m b}}^{T_{h}(t)} C p_{\text {air }}(T) d T\right) d t$

The polynomial equation of $C \mathrm{p}_{\text {air }}(T)$ used is taken from the tables of thermal properties of air provided by the U.S. National Bureau of Standards [36], and written as follows:

$C \mathrm{p}_{\mathrm{air}}(T)=b_{1} T^{4}+b_{2} T^{3}+b_{3} T^{2}+b_{4} T+b_{5}$

with the constants $b_{1}$ to $b_{5}$ given in Table 1 .

It is also possible to calculate the amount of energy that is effectively exchanged between the heated air and the system.

$Q_{\text {exc-ch }}(t)=\int_{0}^{t} \dot{m}(t)\left(\int_{T_{c}(t)}^{T_{h}(t)} C \mathrm{p}_{\text {air }}(T) d T\right) d t$

with $T_{\mathrm{c}}(t)$ the temperature of the last thermocouple inside the packed bed. The quantity of enthalpy transiting through the system and dissipated outside via the vent stack (waste heat) is therefore given by:

$Q_{\text {trans-ch }}(t)=\int_{0}^{t} \dot{m}(t)\left(\int_{T_{\text {amb }}(t)}^{T_{c}(t)} C \mathrm{p}_{\text {air }}(T) d T\right) d t$

Finally, the amount of enthalpy exchanged between the air and the system, but not stored by the alumina, can have been either stored in the vermiculite slabs and the rockwool insulants or dissipated to the ambient air through these insulants. Both are gathered under the term $Q_{\text {loss-ch }}$ and are evaluated by subtraction:

$Q_{\text {loss-ch }}(t)=Q_{\text {air-ch }}(t)-Q_{\text {trans-ch }}(t)-\left(Q_{\text {alum-ch }}(t)-Q_{\text {alum-ch }}(t=0)\right)$.

A fraction of these thermal losses effectively leaves the system by diffusion through the insulants to the ambient air. But the considerable thermal mass of the vermiculite slabs, together with their low thermal conductivity, imply that some part of the enthalpy it stores could be recovered during the discharging phase.

It is common in the literature to find the temperatures expressed as

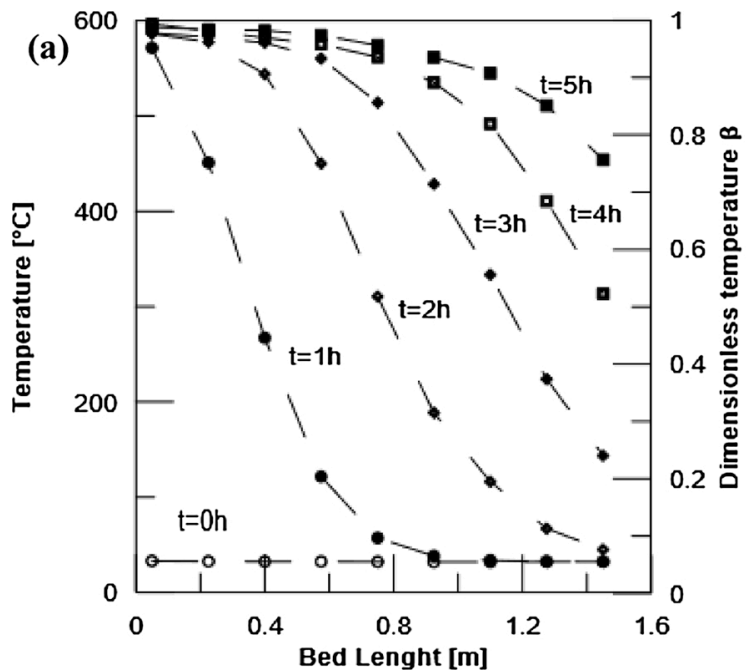

dimensionless quantities. This allows us to compare the behaviour of different systems regardless of the use of different temperatures, and it can be practical to evaluate thermocline thickness on thermal profile graphs. The dimensionless temperature is defined by:

$\beta(t)=\frac{T(t)-T_{a m b}}{T_{H}-T_{a m b}}$

\subsection{Discharging phase}

During the discharge, the ambient air is heated by the ceramics. The delivery of hot air being the purpose of the storage, the energy gained by the ambient air through the packed bed was tracked, using $Q_{\text {exc-di, }}$, calculated with the same equations as for the charging phase. This allows us to define two performance indicators:

The first, named "storage yield", is defined at any given time and compares the heat recovered by the air during the discharging phase with the totalamount of heat exchanged between the air and the system during the charging phase:

$\gamma^{\prime}(t)=\frac{Q_{\text {exc-di }}(t)}{Q_{\text {exc-ch-final }}}$

with $Q_{\text {exc-ch-final }}$ the total enthalpy exchanged by the air at the end of the charging phase.

This indicator tends to 1 if the thermal losses to the environment are limited (adiabatic process), if the enthalpy stored in the vermiculite slabs is recovered, and for a deep discharge, a discharge performed until the outlet temperature $\left(T_{\mathrm{h}}(t)\right)$ is close to the ambient temperature. This indicator can be represented either as a function of time, or as a function of the outlet temperature (numerical or dimensionless) during discharge.

It is an indicator of the ability of the storage system to deliver the enthalpy previously stored. However, it does not take into account the amount of transient enthalpy during charge, considered as irreversibly lost. It is advantageously associated with a second indicator named "cycle efficiency".

Defined at any given time during the discharging phase, this compares the heat recovered by the air with the total available enthalpy injected into the system during the charging phase. It tends to 1 for an infinitesimal thermocline thickness during charge (no transient enthalpy), an adiabatic process (no thermal transfer out of the system) and a deep discharge:

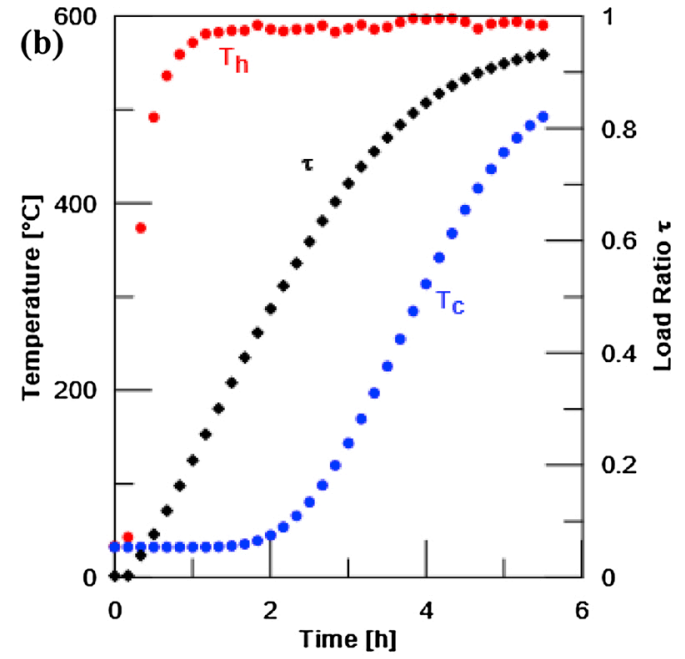

Fig. 4. (a) Thermal profiles along the packed bed, DS trial, charging phase; (b) Variations in inlet ( $\bullet$ ) and outlet temperature ( $\bullet$ ) and load ratio ( $\bullet$ ) over time, DS trial, charging phase. 
$\gamma(t)=\frac{Q_{\text {exc-di }}(t)}{Q_{\text {air-ch-final }}}$

For each experiment, the state of the system and its performance at several outlet temperatures were analysed.

\section{Deep symmetrical cycle}

This section details the results obtained for a cycle composed of a charge at inlet temperature $590^{\circ} \mathrm{C}$, air flow rate $75 \mathrm{~kg} / \mathrm{h}$ and a discharge at $72 \mathrm{~kg} / \mathrm{h}$. The cut-off temperature was set to $T_{\mathrm{c}}=490^{\circ} \mathrm{C}$ for the charging phase. Because the discharge flow rate was close to the charging flow rate, and the cut-off temperature during charge was high, this cycle was named "deep symmetrical", noted DS. Discharge lasted until the packed bed had returned to its initial state.

\subsection{Charge}

The temperature profile at the central position along the bed length is represented on Fig. 4a every hour of the charging phase. It shows the establishment of a thermocline area, and its displacement and thickness variations over time inside the duct. The gradient was noticeably steeper during the first hour of heating and flattened afterwards. This effect is often described as resulting from thermal diffusion along the packed bed. The thermocline is then extracted from the system, implying an increase in the outlet temperature beyond $2 \mathrm{~h}$ of charging.

Fig. $4 \mathrm{~b}$ shows that the inlet temperature reached its maximum after around $45 \mathrm{~min}$ of charging, which is related to the thermal inertia of the elements located before the first thermocouple. The load ratio increased linearly over time during the first few hours. The outlet air flow was at room temperature for the first two hours: during this period, the transient enthalpy was close to zero. The charge was interrupted before the stabilization of the outlet temperature, which would have occurred at a lower level than the inlet temperature, due to heat losses from the system to the outside. The load ratio reached $93 \%$ at the end of the charging phase nonetheless, corresponding to a deep charge of the system. Increasing the duration of the charging phase increases the load ratio of the packed bed, but this does not make it the best management strategy for storage in terms of energy efficiency. The lost enthalpy exiting the system increases with a high load ratio.

To analyse and quantify the system's behaviour, we can represent the energy distribution during the charging phase, for different outlet temperatures, related to different charging phase durations (Fig. 5). The blue bar represents the energy actually stored in the storage materials (alumina), the red bar the energy stored inside the insulants or lost to the ambient air through them, and the green bar the amount of transient enthalpy, all compared with the available enthalpy content of the inlet air.

Fig. 5 demonstrates that for short charging durations (and thus low $T_{\mathrm{c}}(t)$ ), the alumina stored nearly all the available enthalpy provided by the inlet air, up to a point from which transient enthalpy and thermal losses (including enthalpy stored in the vermiculite slabs) increased faster. At the end of the charging phase, $29 \%$ of the available enthalpy had been dissipated as waste heat.

Using air as HTF allows us to integrate the storage system in an open-loop thermal cycle, usefully reducing the complexity and investments inherent to fluid circulation. On the other hand, it implies that the "transient enthalpy" will not be recovered in the discharging phase. As a consequence, deep charges will markedly impair the overall cycle efficiency of the system by increasing transient enthalpy. We will see later that this kind of strategy gives the worst results in terms of cycle efficiency, even when compared with partial load with a "degraded" heat resource (variable flow rate or temperature over time during charge). Clearly then, from a techno-economical point of view, a compromise has necessarily to be found between (i) a high load ratio synonymous with a high storage capacity expressed per unit of storage volume and/or mass of storage solid, and (ii) a high cycle efficiency promoted by a low load ratio.

\subsection{Discharge}

After the charging phase described above, the system was immediately discharged at a flow rate of $72 \mathrm{~kg} / \mathrm{h}$. The standby time between charging and discharging phases was about $12 \mathrm{~min}$, the time required to invert the flow, and so self-discharge and thermocline diffusion over time during standby periods could be neglected and were therefore not studied. The discharge lasted until the outlet temperature $T_{\mathrm{h}}$ had returned to room temperature.

The thermal profiles in the packed bed every hour during discharge (Fig. 6a) showed a steep decrease in the temperatures near the inlet air entrance $(x=1.50 \mathrm{~m})$. This gradient, like for the charging phase, tended to flatten over time. The outlet temperature started decreasing after around $2 \mathrm{~h}$ of discharge, as seen in Fig. $6 \mathrm{~b}$. The inlet temperature decreased quickly (about $0.25 \mathrm{~h}$ ), then stabilized at room temperature. The load ratio decreased linearly during the first $3 \mathrm{~h}$, before tapering off asymptotically. At the end of the discharge, almost all the energy stored in the alumina had been discharged (load ratio $\tau=0$ ).

Fig. 7 shows the time course of the outlet temperature $T_{\mathrm{h}}$ and the cycle efficiency $\gamma$ over time, during the discharging phase. The cycle efficiency increased over time, and tended asymptotically to 0.68 , the maximum value at the end of the discharge. It is of note that most of the energy recovered during the discharge was recovered during the first $2.5 \mathrm{~h}$ of discharge, before the steep decrease in outlet temperature.

This is characteristic of thermocline systems. Given the definition of efficiency $\gamma$, it is impossible to recover the transient enthalpy lost during the previous charge (Fig. 5). The energy that can be recovered during discharge is either stored in the packed bed, or inside the insulants, respectively evaluated at $63 \%$ and $8 \%$ of inlet air enthalpy content during the charging phase. Therefore, the maximum reachable by $\gamma$ was limited to 0.71 , assuming the energy stored in the structural material can be fully recovered during discharging phase. This means that for this studied case, most of the enthalpy considered as thermal losses was actually stored in the vermiculite wall and successfully recovered during discharge.

\subsection{Fluid flow homogeneity}

Horizontal packed beds can present the drawback of developing a

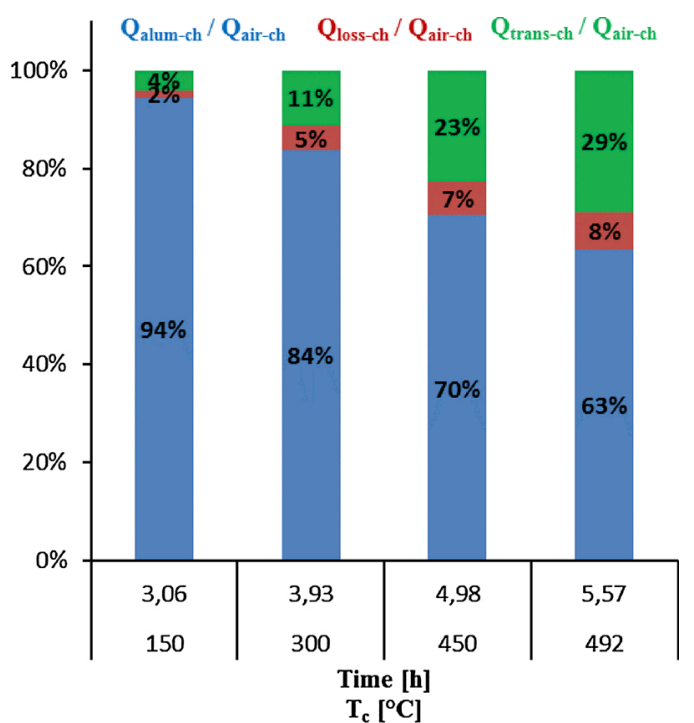

Fig. 5. Enthalpy distributions for different outlet temperatures, DS trial, charging phase. 

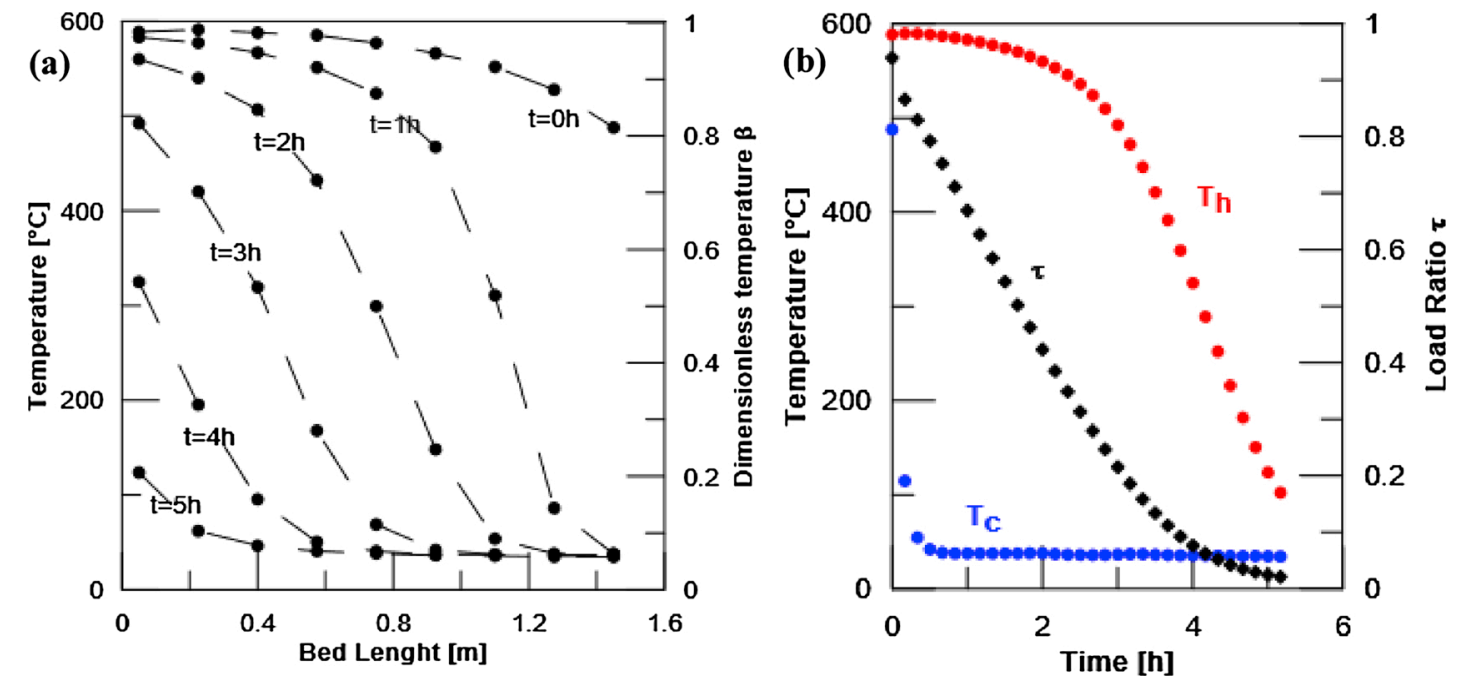

Fig. 6. (a) Thermal profiles along the packed bed, DS trial, discharging phase, (b) Variations in inlet ( $\bullet$ ) and outlet ( $\bullet$ ) temperature and load ratio ( $\bullet$ ) over time, DS trial, discharging phase.

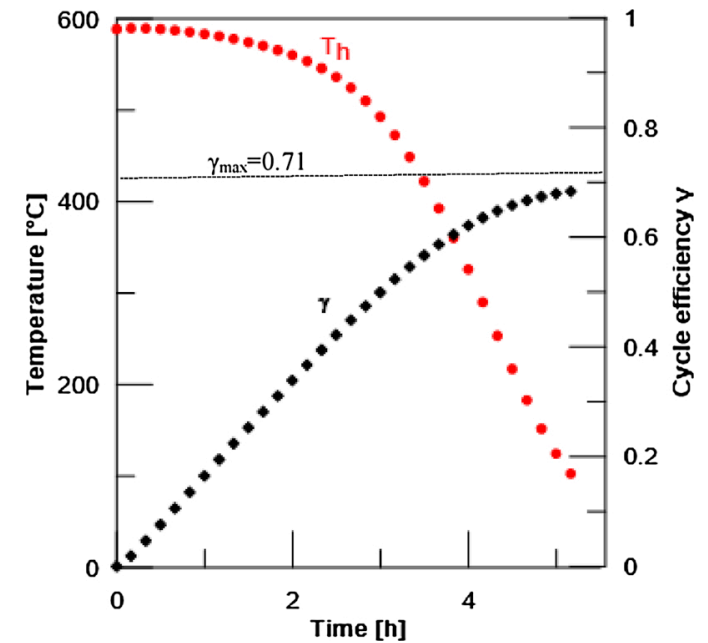

Fig. 7. Outlet temperature and cycle efficiency variations over time, DS trial, discharging phase.

high-porosity layer at the top of the packed bed, generating a preferential path for the air. If so, an important thermal gradient will appear on the section of the packed bed ( $y, z$ plane). Comparing the temperatures on a section can be relevant to determine whether this preferential path exists or not, and if it is significant. The design and building of the pilot took this issue into account and integrated some technical solutions to avoid this effect to occur, however it is necessary to confirm that no significant radial thermal gradient appeared. The Fig. 8 represent the evolution over time of several thermocouples having the same $\mathrm{x}$ coordinates, but different $\mathrm{y}, \mathrm{z}$ coordinates, for 3 different positions inside the packed bed, during the reference DS charging phase. They were no major temperature differences between the thermocouples at a same $\mathrm{x}$ coordinate. Such behavior also observed during discharge pointed out that the horizontal orientation of the storage did not generate enough preferential pathways for air for it to bypass the packed bed and create a thermal gradient on the section of the packed bed. In the same way, the temperature profiles indicated that the horizontal orientation did not generate any kind of stratification as the temperatures were almost uniform at a same $\mathrm{x}$ coordinate. No significant differences were observed between thermocouples situated at the top and the bottom of the tank.

\section{Influence of discharge flow rate on performance}

This section details the results obtained by setting three different discharge flow rates, with all other parameters constant (same mass flow rate during the charging phase, same cut-off criteria and same inlet temperature during charge). The working conditions are summarized in Table 2.

The close similarities in operational conditions during charge imply that the differences in behaviour and performance will be related only to the mass flow rate during discharge. The slight differences in mass flow rate and cut-off criteria during charge were due to command and control limits on the pilot. Although the differences in charging conditions were very small, the outcome of these charges was measured. Fig. 9, which represents the temperature profiles along the packed bed at the end of the charging phase for the three charges, demonstrates that they were almost identical.

It also clearly shows that the thermal gradient, non-existent for the first $0.8 \mathrm{~m}$, was steep past $1.15 \mathrm{~m}$. Most of the gradient was located along the last $25 \mathrm{~cm}$ of the packed bed. Replicability was also checked for the global thermal balances. At the end of the charge, for all three cases, energy stored in the alumina (Eq. 2) was $63-65 \%$ of the maximum enthalpy exchangeable by the air (Eq. 5), while transient enthalpies lay in the range $29-27 \%$. The proportion of thermal losses were equal for all three charges, at $8 \%$ of the total available enthalpy. The maximum cycle efficiencies were thus limited to around 0.7. All these results underline the reliability and reproducibility of the experiments conducted.

Outlet temperature profiles during the discharges are shown in Fig. 10a. As expected, an increase in the discharge flow rate shortened the time required to discharge the storage system, thus increasing the delivered power. Increasing the flow rate might be expected to expand the thermocline area due to shorter residence time, thus decreasing the efficiency of the storage for a given outlet temperature during discharge. This was not the case: as shown in Fig. 10b, for a flow rate ranging from 39 to $123 \mathrm{~kg} / \mathrm{h}$ and the corresponding superficial fluid velocity from 0.089 to $0.281 \mathrm{~m} / \mathrm{s}$ expressed at NPT conditions, at a given outlet temperature, the cycle efficiencies of the three different cycles were the same

A value of 0.7 was almost reached at the end of the discharges. Basically, the coupling between the heat flux conveyed by forced convection by the air flow and the heat flux exchanged with the storage solid was not modified in the flow rate range studied. For these three discharges, the average delivered power (calculated as $P_{\text {avg }}=Q_{\text {exc-d }} /$ $\Delta t$ ) ranged from respectively 35 to $120 \mathrm{~kW} / \mathrm{m}^{3}$ for $T_{\mathrm{h}}=150^{\circ} \mathrm{C}$ during 

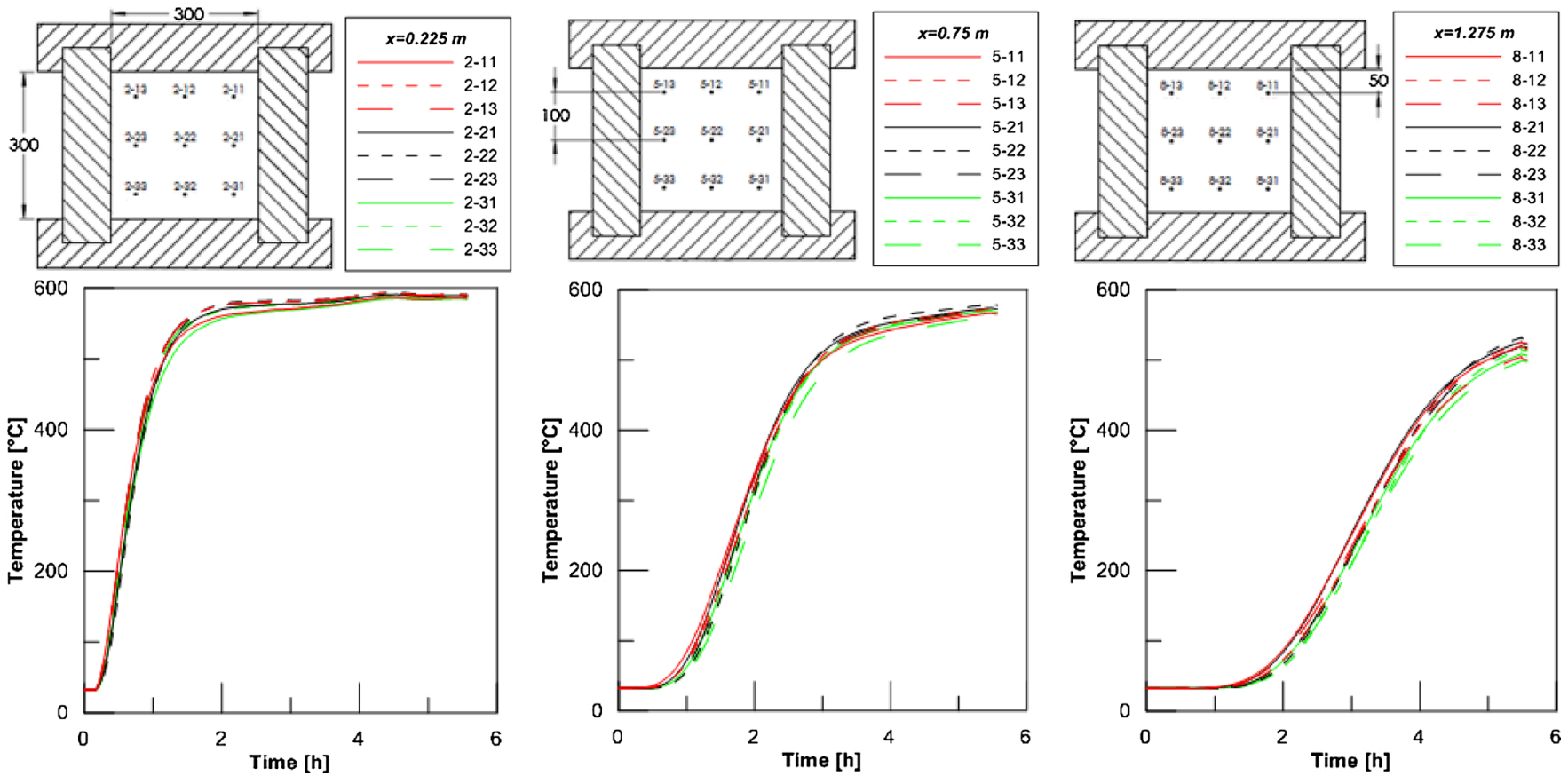

Fig. 8. Radial (y,z plane) evolution of températures inside the packed bed. First row : Positions of the thermocouples. Second row : DS, Charging Phase.

discharging phase, for $Q_{\text {exc-d }}\left(150^{\circ} \mathrm{C}\right)$ being $42.5 \mathrm{kWh} \pm 2 \%$ without decreasing the cycle efficiency. This flexibility is especially relevant for industrial implementation (coupling processes, using the thermocline storage as a buffer).

The fact that the performance depends mostly on the initial state prior to discharge, and the corresponding amount of transient enthalpy, allows system predictability and offers different potential uses of the stored heat (coupling batch processes, warming up a batch oven, etc.).

\section{Influence of poor heat quality during the charging phase on performance}

Waste heat being a by-product, it is not as controlled and stabilized as products are. In many cases (especially for discontinuous processes), exhaust temperature and mass flow rate can vary over time. This also occurs in the field of CSP, for which weather can induce fast, severe variations in operating conditions. A storage device for recovering and storing these flows must therefore be able to sustain variations in operating conditions during the charging phase, without excessively degrading its overall cycle performance. The Deep Symmetrical experiment (DS) was used as a reference case, with its charging temperature and mass flow rate being kept constant. To investigate the influence of an inconsistent mass flow rate during the charging phase, two experiments were set up (Table 3).

The FRS trial imposed a steep decrease in mass flow rate during charge: after being set at $75 \mathrm{~kg} / \mathrm{h}$ during the first $2 \mathrm{~h}$, the flow rate was then set at $37 \mathrm{~kg} / \mathrm{h}$ until the end of the charging phase. To investigate the influence of fluctuant mass flow rate during charge, the FRO trial was set up. The inlet mass flow rate during charge varied from 64 to

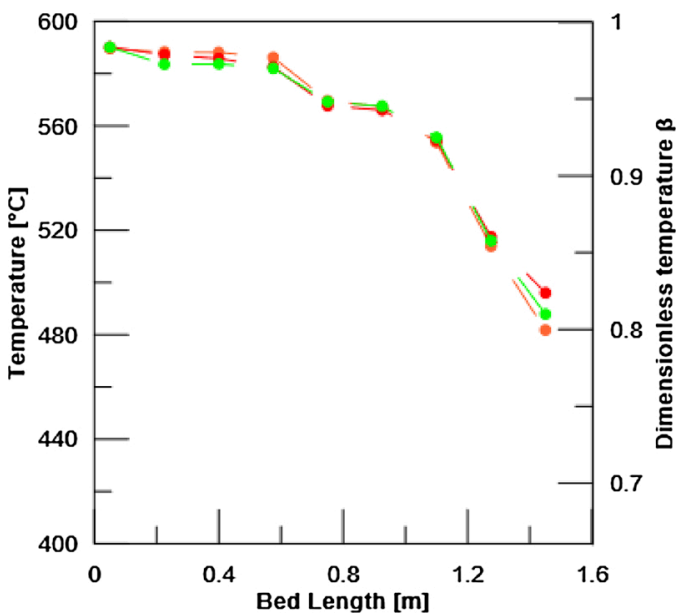

Fig. 9. Thermal profiles along the packed bed, at the end of the charging phase

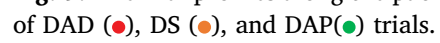

$46 \mathrm{~kg} / \mathrm{h}$, with a $0.5 \mathrm{~h}$ half-period. The last trial, TO, was designed to investigate the effect of fluctuating inlet temperature on performance: the inlet temperature oscillated around a mean temperature of $505^{\circ} \mathrm{C}$ (considered as a reference for $Q_{\text {alum-max }}$ ) from 570 to $440^{\circ} \mathrm{C}$ with a $0.5 \mathrm{~h}$ half-period.

\subsection{Charging phase}

Fig. 11 details the load ratio variation for these experiments, as a

Table 2

Operational conditions for DS, DAD and DAP cycles.

\begin{tabular}{|c|c|c|c|c|c|c|c|}
\hline \multirow[b]{2}{*}{ Code } & \multicolumn{3}{|c|}{ Charging conditions } & \multicolumn{4}{|c|}{ Discharging conditions } \\
\hline & $\mathrm{T}_{\mathrm{H}}\left[{ }^{\circ} \mathrm{C}\right]$ & Mass flow rate $[\mathrm{kg} / \mathrm{h}]$ & Cut-off criterion & $\mathrm{T}_{\mathrm{C}}\left[{ }^{\circ} \mathrm{C}\right]$ & Mass flow rate $[\mathrm{kg} / \mathrm{h}]$ & Superficial velocity (NPT conditions) $[\mathrm{m} / \mathrm{s}]$ & Cut-off criterion \\
\hline DAD & 590 & 72 & $T_{\mathrm{c}}=488^{\circ} \mathrm{C}$ & Amb. & 39 & 0.089 & NA \\
\hline DS & 590 & 75 & $T_{\mathrm{c}}=492{ }^{\circ} \mathrm{C}$ & Amb. & 72 & 0.165 & NA \\
\hline DAP & 590 & 76 & $T_{\mathrm{c}}=496^{\circ} \mathrm{C}$ & Amb. & 123 & 0.281 & NA \\
\hline
\end{tabular}



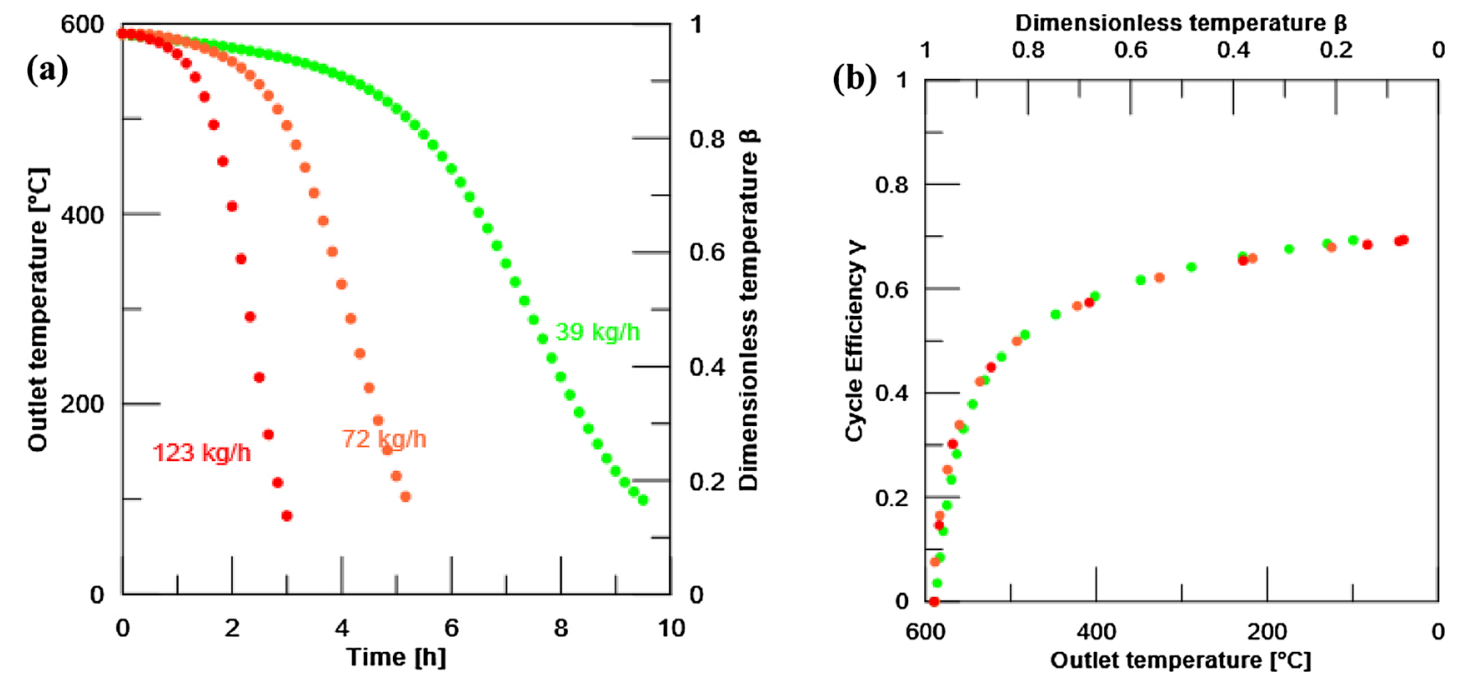

Fig. 10. (a) Outlet temperature as a function of time, at $123(\bullet), 72(\bullet), 39(\bullet) \mathrm{kg} / \mathrm{h}$ discharge flow rate, (b) Cycle efficiency as a function of outlet temperature, at $123(\bullet), 72(\bullet), 39(\bullet) \mathrm{kg} / \mathrm{h}$ discharge flow rate.

Table 3

Operating parameters (influence of degraded heat resource on overall performance).

\begin{tabular}{|c|c|c|c|c|c|c|}
\hline & \multicolumn{3}{|l|}{ CHARGE } & \multicolumn{3}{|l|}{ DISCHARGE } \\
\hline & Inlet Temperature $T_{\mathrm{H}}\left[{ }^{\circ} \mathrm{C}\right]$ & Flow rate $[\mathrm{kg} / \mathrm{h}]$ & Cut-off Criterion $\left(T_{\mathrm{c}}\right)\left[{ }^{\circ} \mathrm{C}\right]$ & Inlet Temperature & Flow rate $[\mathrm{kg} / \mathrm{h}]$ & Cut-off criterion \\
\hline DS & 590 & 75 & 492 & Amb. & 72 & NA \\
\hline FRS & 590 & $75(2 \mathrm{~h})$, then 37 & 309 & Amb. & 70 & NA \\
\hline FRO & 590 & 64-46 (half period $0.5 \mathrm{~h}$ ) & 269 & Amb. & 70 & NA \\
\hline TO & $570-440$ (half period $0.5 \mathrm{~h}$ ) & 66 & 395 & Amb. & 71 & NA \\
\hline
\end{tabular}

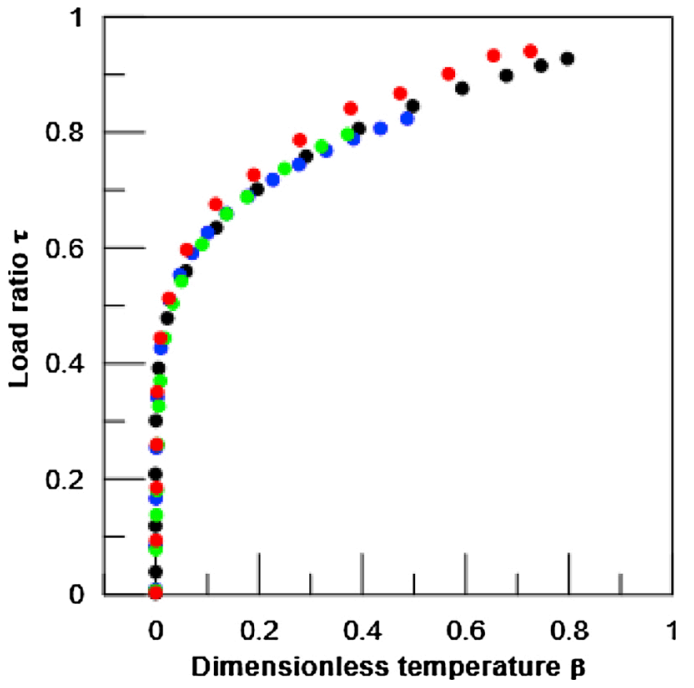

Fig. 11. Load ratio as a function of dimensionless outlet temperature for DS (•), FRS (•), FRO (•) and TO (•).

function of dimensionless outlet temperature during charge. In our experimental domain, it is of note that for a given outlet dimensionless temperature, the load ratio did not depend on the stability of flow rate, FRS, FRO and DS curves being identical.

This means that in this experimental domain, the system is not sensitive to instabilities of flow rate, and that the thermocline is not affected by such instabilities. The main effect of flow rate instability was to increase charging duration. For the TO charge $Q_{\text {alum_max }}$ was calculated with $T_{\mathrm{H}}$ set at $505^{\circ} \mathrm{C}$, the mean inlet temperature. The load ratio of the TO trial was slightly higher for a given outlet temperature but similar to the other trials for a given dimensionless temperature.

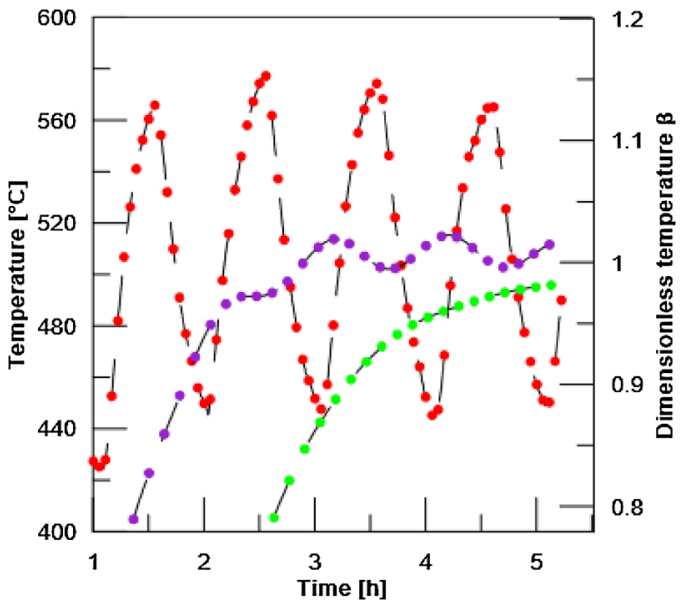

Fig. 12. Attenuation and dephasing of the inlet air temperature variation along the packed bed. $\mathrm{x}=0.05 \mathrm{~m}(\bullet), \mathrm{x}=0.4 \mathrm{~m}(\bullet)$ and $\mathrm{x}=0.75 \mathrm{~m}(\bullet)$

This charge showed interesting behaviour: the temperature oscillations of the inlet air caused oscillations of the temperature of the packed bed, which were attenuated along the bed (Fig. 12).

Beyond $x=0.75 \mathrm{~m}$, the temperature oscillations of the inlet air had almost no effect on the temperature of the alumina. The temperature of the packed bed tended to stabilize around the average temperature during charge $\left(505^{\circ} \mathrm{C}\right)$. All the trials revealed the same pattern as DS for enthalpy distribution. For short charging duration, most of the available enthalpy provided by the air was stored inside the packed bed, with longer charging times increasing the proportions of thermal losses and transient enthalpy. However, the evolution of the proportion of transient enthalpy as a function of the dimensionless outlet temperature was similar for DS, FRS and FRO trials, as shown in Fig. 13. This means 


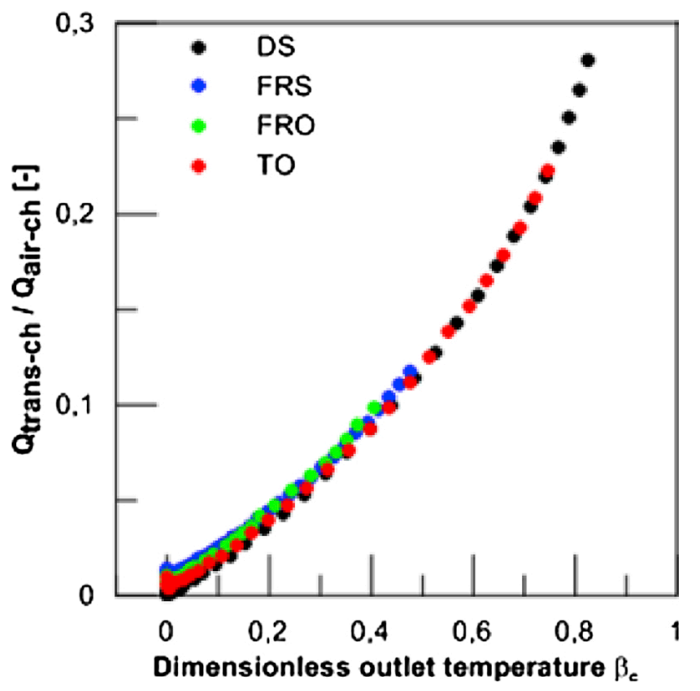

Fig. 13. Transient enthalpy proportion as a function of dimensionless outlet temperature for DS $(\bullet)$, FRS $(\bullet)$, FRO $(\bullet)$ and TO $(\bullet)$.

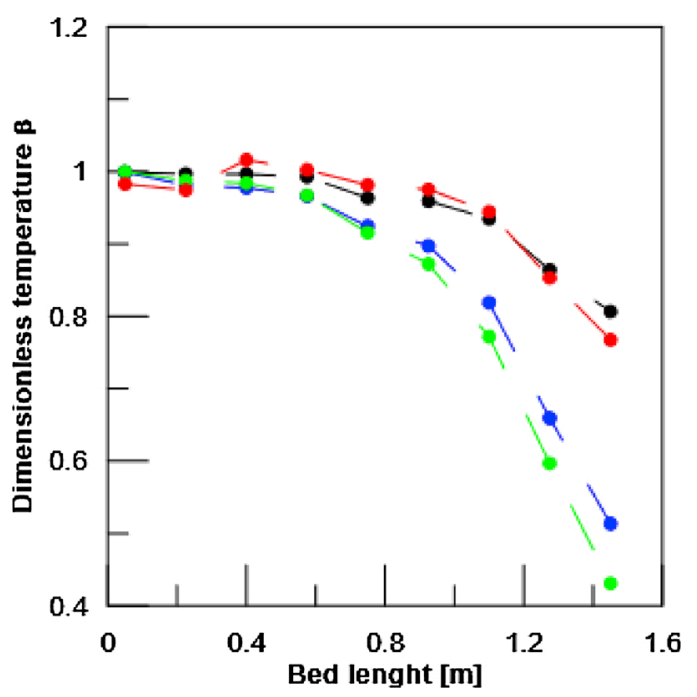

Fig. 14. Thermal profile along the packed bed, end of charging phase for DS (• ), FRS $(\bullet)$, FRO (•) and TO $(\bullet)$.

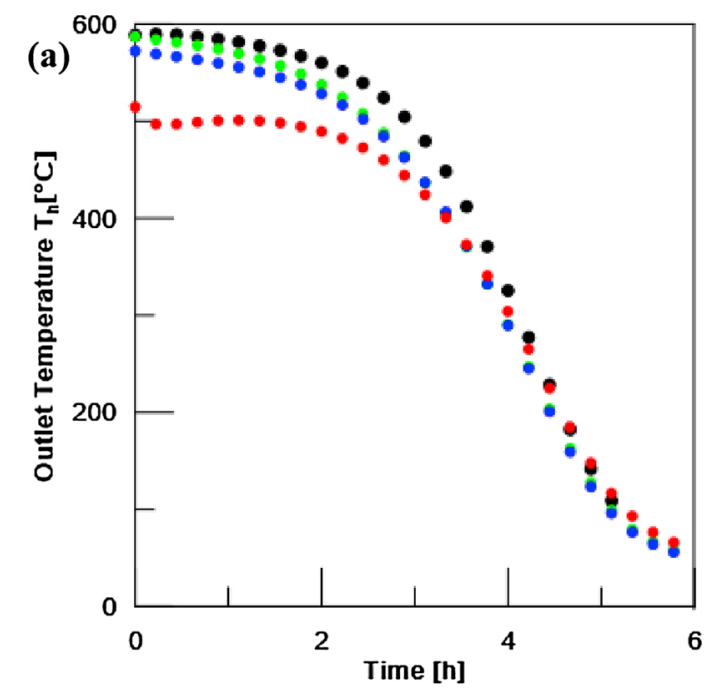

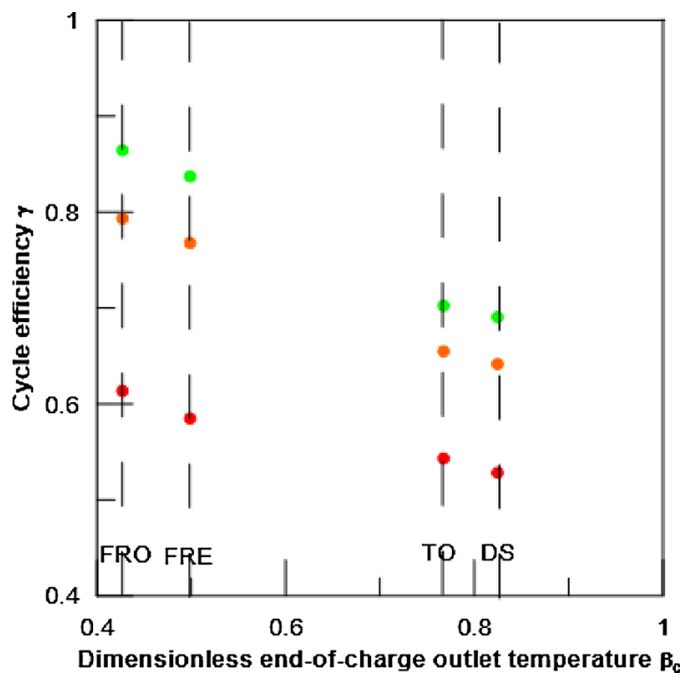

Fig. 16. Cycle efficiency for $0.8(\bullet), 0.5(\bullet)$ and $0.2(\bullet)$ dimensionless outlet temperature, as a function of end-of-charge dimensionless outlet temperature.

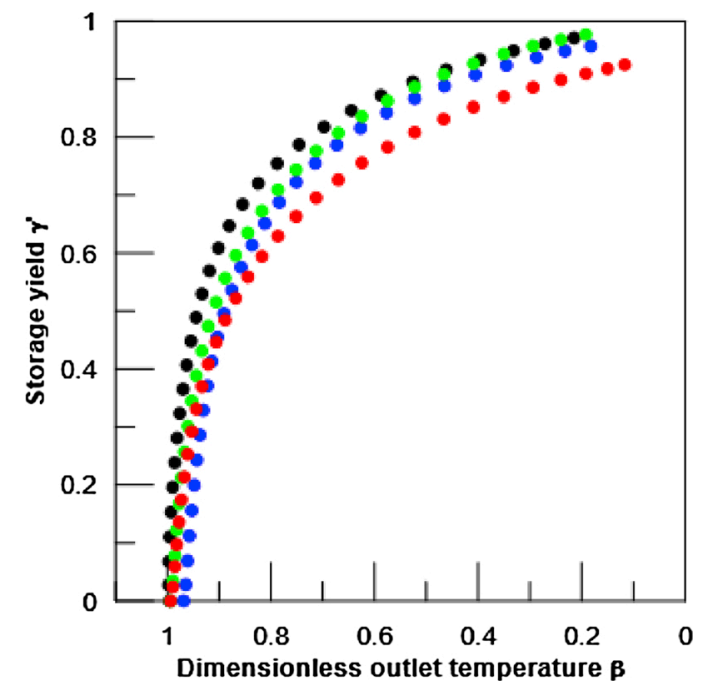

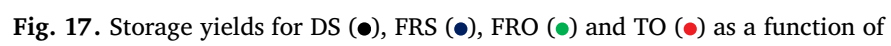
dimensionless outlet temperature during discharge.

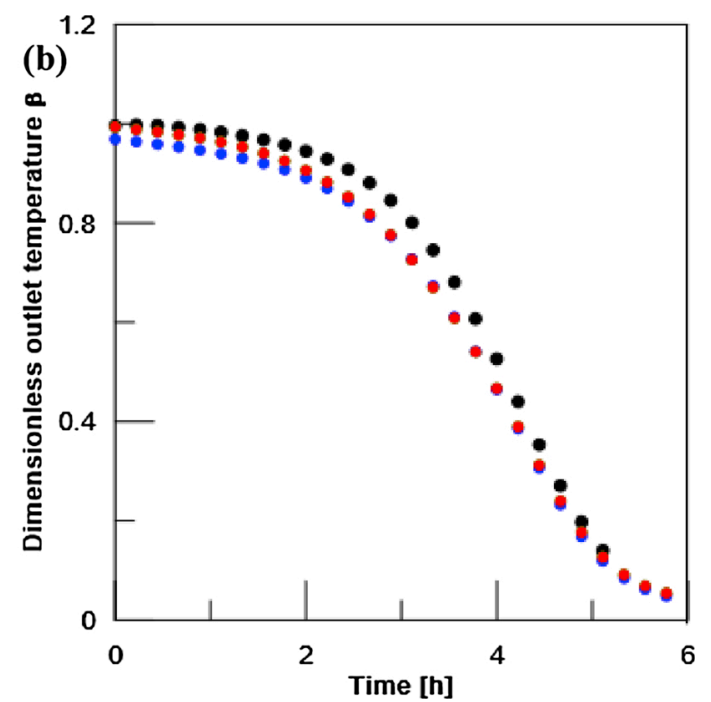

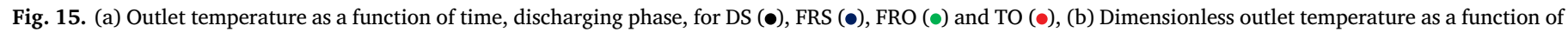
time, discharging phase, for DS $(\bullet)$, FRS $(\bullet)$, FRO $(\bullet)$ and TO $(\bullet)$. 
that their maximal cycle efficiency will only depend on the depth of the charge and not be affected by variations of flow rate during charge. For technical reasons, the cut-off temperature criteria were different for each trial (Table 3), resulting in very different ratios of transient enthalpy for the different trials, as well as different thermal profiles along the packed bed, as seen in Fig. 14.

We note that the thermal profiles in the packed bed for TO and DS trials were relatively similar. These two trials were performed with close cut-off conditions when expressed with the non-dimensional temperature $\beta(\beta=0.81$ for DS and $\beta=0.77$ for TO). FRS and FRO, with $\beta$ respectively equal to 0.50 and 0.43 exhibited steeper gradients near the exit of the bed.

\subsection{Discharging phase}

The time course of outlet temperature for these trials is shown in Fig. 15a. It is of note that the DS, FRS and FRO trials exhibited the same behaviour, so the outlet temperature variation over time during discharge did not seem to be strongly impacted by the differences in operating conditions during charge. Obviously, with a mean high inlet temperature during charge of $505^{\circ} \mathrm{C}$, TO delivered a lower temperature, but with the same behaviour as the other trials, which is evident in Fig. 15b, using dimensionless outlet temperature. Close outlet temperature profile during discharge is a strong indicator of the ability of a system to manage poor heat quality during charge.

As stated previously, the charging phases were stopped at different cut-off temperatures, resulting in different ratios of transient enthalpy. Their cycle efficiencies were therefore necessarily different. However, it is noteworthy (Fig. 16) that cycle efficiency as a function of cut-off temperature during charge seems not to have been affected by a "poor heat quality" resource during this step. Whatever the charging conditions (mass flow changes, temperature oscillation temperature) the efficiency profiles fitted different curves dependent only on the cut-off criteria during charge and discharge.

Fig. 13 shows that the transient enthalpy lost during charge is not dependent on the quality of the heat resource. The storage yield $\gamma^{\prime}$ is therefore a relevant indicator for bringing to light a potential degradation of heat recovery during a discharge following storage of such a resource. Fig. 17 shows that for a given dimensionless outlet temperature, the differences in storage yields of FRS and FRO were negligible, meaning that the nature of the instability of the mass flow rate during charge (step or oscillation) seems to have had no influence on the storage behaviour.

The difference between FRS and FRO and DS can also be considered as minor, and the curves tend to converge for deep discharges. A degraded mass flow rate during charge did not significantly modify the behaviour of the system. TO exhibited slightly lower performance in terms of storage yield, around 5-10 points lower than the other trials, for a given dimensionless outlet temperature, although this difference was only $2-5$ points for the same dimensional outlet temperature. This indicates that degraded heat input during charge has little influence on the system's behaviour, so that cut-off temperatures during charge are more meaningful parameters for assessing the system's overall performance (cycle efficiency).

\section{Conclusions}

A horizontal air/ceramic pilot thermocline heat storage system was built and operated according to different scenarios chosen as relevant for industrial use. It was found that this system could deliver the stored heat at different powers, ranging from 35 to $120 \mathrm{~kW} / \mathrm{m}^{3}$ (deep discharges), without decreasing overall cycle efficiency. By increasing the cut-off temperature during discharge, higher average power delivery was achievable, at the cost of decreased efficiency, more enthalpy being left inside the storage system at the end of the discharge. The different discharge flow rates all allowed recovery of almost all exchanged enthalpy during the charging phase, and thereby reached a cycle efficiency of 0.7 . This efficiency could probably be increased by lowering the cut-off temperature during charge, which would reduce the raction of transient enthalpy. Most of the recovered enthalpy was delivered above $500{ }^{\circ} \mathrm{C}$ (corresponding to a dimensionless temperature of 0.83 ), highlighting the fact that the thermocline was relatively thin. Beside these quantitative experimental figures, a major result is that a horizontal positioning of air/ceramic storage tank is fully in agreement with a thermocline working mode.

It was also found that degraded flow rate during the charging phase had no effect on the load ratio (and thus thermocline thickness), reaching for example $75 \%$ for an outlet temperature of $250{ }^{\circ} \mathrm{C}$. The main operational parameter for performance was the cut-off temperature during charge; its influence on the transient enthalpy was not affected by instabilities of flow rate. Finally, the almost constant storage yield at a given outlet temperature, for non-uniform flow rates during charge, demonstrates the ability of the system to manage degraded heat resources.

A heat resource with fluctuating temperature can also be advantageously stored by the system, with smoothing of the thermal profile in the packed bed. The performance was still high in this scenario, though slightly lower than for the others. This is of particular interest for electricity production based on degraded waste heat resources: these resources are barely used for electricity production because most of the components involved in it are very sensitive to temperature stability (exchangers, boilers, turbines, etc.). The fact that thermocline systems could be used as buffers to deliver stable temperature offers potential applications for the gainful use of waste heat through electricity production.

\section{Acknowledgments}

This work was supported by the Programme "Investissements d'avenir" (Investment for the Future) of the Agence Nationale de la Recherche (National Agency for Research) of the French State under award number ANR-10-LABX-22-01-SOLSTICE. The author also thanks Eco-Tech Ceram for their scientific, material and financial support.

\section{References}

[1] ADEME, La chaleur fatale industrielle, (2015).

[2] U.S. Department of Energy, Waste heat Recovery: Technology and Opportunities in U.S. Industry, (2008).

[3] N.E. Rafidi, Thermodynamic Aspects and Heat Transfer Characteristics of HiTAC Furnaces With Regenerators, Royal Institute of Technology, 2005.

[4] Z. Utlu, Investigation of the potential for heat recovery at low, medium, and high stages in the Turkish industrial sector (TIS): an application, Energy 81 (2015) 394-405, https://doi.org/10.1016/j.energy.2014.12.052.

[5] P. Klein, T.H. Roos, T.J. Sheer, Parametric analysis of a high temperature packed bed thermal storage design for a solar gas turbine, Sol. Energy 118 (2015) 59-73, https://doi.org/10.1016/j.solener.2015.05.008.

[6] E. Barbour, D. Mignard, Y. Ding, Y. Li, Adiabatic compressed air energy storage with packed bed thermal energy storage, Appl. Energy 155 (2015) 804-815, https://doi.org/10.1016/j.apenergy.2015.06.019.

[7] S.A. Zavattoni, M.C. Barbato, A. Pedretti, G. Zanganeh, A. Steinfeld, High temperature rock-bed TES system suitable for industrial-scale CSP plant - CFD analysis under charge/discharge cyclic conditions, Energy Procedia 46 (2014) 124-133, https://doi.org/10.1016/j.egypro.2014.01.165.

[8] A. Kere, V. Goetz, X. Py, R. Olives, N. Sadiki, E. Mercier, Dynamic behavior of a sensible-heat based thermal enegy storage under cycling, SolarPACES 2013, Las Vegas, USA, 2013 p. 2013.

[9] A. Kéré, Stockage d'électricité par compression adiabatique d'air, UPVD, 2014.

[10] T. Fasquelle, Q. Falcoz, P. Neveu, J.F. Hoffmann, Numerical simulation of a 50 MWeparabolic trough power plant integrating a thermocline storage tank, Energy Convers. Manage. 172 (2018) 9-20, https://doi.org/10.1016/j.enconman.2018.07. 006.

[11] T. Fasquelle, Q. Falcoz, P. Neveu, J.F. Hoffmann, A temperature threshold evaluation for thermocline energy storage in concentrated solar power plants, Appl. Energy 212 (2018) 1153-1164, https://doi.org/10.1016/j.apenergy.2017.12.105.

[12] M. Mahmood, A. Traverso, A.N. Traverso, A.F. Massardo, D. Marsano, C. Cravero, Thermal energy storage for CSP hybrid gas turbine systems: dynamic modelling and experimental validation, Appl. Energy 212 (2018) 1240-1251, https://doi.org/10. 1016/j.apenergy.2017.12.130. 
[13] J.F. Hoffmann, T. Fasquelle, V. Goetz, X. Py, A thermocline thermal energy storage system with filler materials for concentrated solar power plants: experimental data and numerical model sensitivity to different experimental tank scales, Appl. Therm. Eng. 100 (2016) 753-761, https://doi.org/10.1016/j.applthermaleng.2016.01.110.

[14] K.V. Manu, P. Anand, U.K. Chetia, S. Basu, Effects of instabilities and coherent structures on the performance of a thermocline based thermal energy storage, Appl Therm. Eng. 87 (2015) 768-778, https://doi.org/10.1016/j.applthermaleng.2015. 05.072 .

[15] E.V. Votyakov, A.M. Bonanos, Algebraic model for thermocline thermal storage tank with filler material, Sol. Energy 122 (2015) 1154-1157, https://doi.org/10 1016/j.solener.2015.10.047.

[16] A. Kéré, V. Goetz, X. Py, R. Olives, N. Sadiki, Modeling and integration of a heat storage tank in a compressed air electricity storage process, Energy Convers. Manage. 103 (2015) 499-510, https://doi.org/10.1016/j.enconman.2015.06.033.

[17] A. Kere, N. Sadiki, X. Py, V. Goetz, Applicability of thermal energy storage recycled ceramics to high temperature and compressed air operating conditions, Energy Convers, Manage. 88 (2014) 113-119, https://doi.org/10.1016/j.enconman.2014. 08.008 .

[18] C.B. Andrea Gutierrez, Laia Miró, Antoni Gil, Javier Rodríguez-Aseguinolaza, L.F.C. Nicolas Calvet, Xavier Py, A. Inés Fernández, Mario Grágeda, Svetlana Ushak, Review on industrial waste and by-product materials revalorization as thermal energy storage (TES) materials, Renew. Sustain. Energy Rev. (2016) 763-783, https://doi.org/10.1016/j.rser.2015.12.071 In Press.

[19] X. Py, N. Calvet, R. Olives, A. Meffre, P. Echegut, C. Bessada, et al., Recycled material for sensible heat based thermal energy storage to be used in concentrated solar thermal power plants, J. Sol. Energy Eng. 133 (2011) 031008, , https://doi. org/10.1115/1.4004267.

[20] F. Motte, S.L. Bugler-Lamb, Q. Falcoz, X. Py, Numerical study of a structured thermocline storage tank using vitrified waste as filler material, Energy Procedia 49 (2013) 935-944, https://doi.org/10.1016/j.egypro.2014.03.101.

[21] a. Kere, N. Sadiki, X. Py, V. Goetz, Applicability of thermal energy storage recycled ceramics to high temperature and compressed air operating conditions, Energy Convers. Manage. 88 (2014) 113-119, https://doi.org/10.1016/j.enconman.2014. 08.008.

[22] D. López-González, J.L. Valverde, P. Sánchez, L. Sanchez-Silva, Characterization of different heat transfer fluids and degradation study by using a pilot plant device operating at real conditions, Energy 54 (2013) 240-250, https://doi.org/10.1016/j. energy.2013.01.056.

[23] J. Yu, M. Zhang, W. Fan, Y. Zhou, G. Zhao, Study on performance of the ball packedbed regenerator: experiments and simulation, Appl. Therm. Eng. 22 (2002) 641-651, https://doi.org/10.1016/S1359-4311(01)00116-8.

[24] T. Esence, A. Bruch, S. Molina, B. Stutz, J.F. Fourmigué, A review on experience feedback and numerical modeling of packed-bed thermal energy storage systems, Sol. Energy 153 (2017) 628-654, https://doi.org/10.1016/j.solener 2017.03.032.

[25] A.M. Bonanos, E.V. Votyakov, Sensitivity analysis for thermocline thermal storage tank design, Renew. Energy 99 (2016) 764-771, https://doi.org/10.1016/j.renene. 2016.07.052.

[26] A. Tinaikar, S. Advaith, U.K. Chetia, K.V. Manu, S. Basu, Spatio-temporal disruption of thermocline by successive laminar vortex pairs in a single tank thermal energy storage, Appl. Therm. Eng. 109 (2016) 924-935, https://doi.org/10.1016/j. applthermaleng.2016.04.105.

[27] K.V. Manu, P. Deshmukh, S. Basu, Rayleigh-Taylor instability in a thermocline based thermal storage tank, Int. J. Therm. Sci. 100 (2016) 333-345, https://doi. org/10.1016/j.ijthermalsci.2015.10.016.

[28] B. Grange, C. Dalet, Q. Falcoz, A. Ferrière, G. Flamant, Impact of thermal energy storage integration on the performance of a hybrid solar gas-turbine power plant, Appl. Therm. Eng. 105 (2016) 266-275, https://doi.org/10.1016/j. applthermaleng.2016.05.175.

[29] P. Klein, T.H. Roos, T.J. Sheer, Experimental investigation into a packed bed thermal storage solution for solar gas turbine systems, Energy Procedia 49 (2013) 840-849, https://doi.org/10.1016/j.egypro.2014.03.091.

[30] G. Zanganeh, a. Pedretti, a. Haselbacher, a. Steinfeld, Design of packed bed thermal energy storage systems for high-temperature industrial process heat, Appl. Energy 137 (2015) 812-822, https://doi.org/10.1016/j.apenergy.2014.07.110.

[31] E. Erdim, O. Akgiray, I. Demir, A revisit of pressure drop-flow rate correlations for packed beds of spheres, Powder Technol. 283 (2015) 488-504, https://doi.org/10. 1016/j.powtec.2015.06.017.

[32] M.T. Zarrinehkafsh, S.M. Sadrameli, Simulation of fixed bed regenerative heat exchangers for flue gas heat recovery, Appl. Therm. Eng. 24 (2004) 373-382, https:// doi.org/10.1016/j.applthermaleng.2003.08.005.

[33] G. Zanganeh, A. Pedretti, S. Zavattoni, M. Barbato, A. Steinfeld, Packed-bed thermal storage for concentrated solar power - Pilot-scale demonstration and industrialscale design, Sol. Energy 86 (2012) 3084-3098, https://doi.org/10.1016/j.solener. 2012.07.019.

[34] E.C. Nsofor, G.A. Adebiyi, Measurements of the gas-particle convective heat transfer coefficient in a packed bed for high-temperature energy storage, Exp. Therm. Fluid Sci. 24 (2001) 1-9, https://doi.org/10.1016/S0894-1777(00)00047-9.

[35] P. Auerkari, Mechanical and physical properties of engineering alumina ceramics, Tech. Res. Cent. Finl. 1792 (1996) 26.

[36] J. Hilsenrath, C.W. Beckett, W.S. Benedict, L. Fano, H.J. Hoge, J.F. Masi, et al., Circular of the Bureau of Standards no. 564: Tables of Thermal Properties of Gases Comprising Tables of Thermodynamic and Transport Properties of Air, Argon, Carbon Dioxide, Carbon Monoxide Hydrogen, Nitrogen, Oxygen, and Steam, (1955) 